Atmos. Chem. Phys., 13, 3811-3823, 2013

www.atmos-chem-phys.net/13/3811/2013/

doi:10.5194/acp-13-3811-2013

(c) Author(s) 2013. CC Attribution 3.0 License.

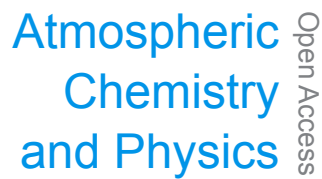

\title{
Montreal Protocol Benefits simulated with CCM SOCOL
}

\author{
T. Egorova ${ }^{1}$, E. Rozanov ${ }^{1,2}$, J. Gröbner ${ }^{1}$, M. Hauser ${ }^{2}$, and W. Schmutz ${ }^{1}$ \\ ${ }^{1}$ PMOD/WRC, Davos, Switzerland \\ ${ }^{2}$ IAC ETH, Zurich, Switzerland \\ Correspondence to: T. Egorova (tania.egorova@pmodwrc.ch)
}

Received: 12 June 2012 - Published in Atmos. Chem. Phys. Discuss.: 10 July 2012

Revised: 4 March 2013 - Accepted: 14 March 2013 - Published: 10 April 2013

\begin{abstract}
Ozone depletion is caused by the anthropogenic increase of halogen-containing species in the atmosphere, which results in the enhancement of the concentration of reactive chlorine and bromine in the stratosphere. To reduce the influence of anthropogenic ozone-depleting substances (ODS), the Montreal Protocol was agreed by Governments in 1987, with several Amendments and Adjustments adopted later. In order to assess the benefits of the Montreal Protocol and its Amendments and Adjustments (MPA) on ozone and $U V$ radiation, two different runs of the chemistry-climate model (CCM) SOCOL have been carried out. The first run was driven by the emission of ozone depleting substances (ODS) prescribed according to the restrictions of the MPA. For the second run we allow the ODS to grow by $3 \%$ annually. We find that the MPA would have saved up to $80 \%$ of the global annual total ozone by the end of the 21 st century. Our calculations also show substantial changes of the stratospheric circulation pattern as well as in surface temperature and precipitations that could occur in the world without MPA implementations. To illustrate the changes in UV radiation at the surface and to emphasise certain features, which can only be seen for some particular regions if the influence of the cloud cover changes is accounted for, we calculate geographical distribution of the erythemally weighted irradiance $\left(E_{\text {ery }}\right)$. For the no Montreal Protocol simulation $E_{\text {ery }}$ increases by factor of 4 to 16 between the 1970s and 2100 . For the scenario including the Montreal Protocol it is found that UV radiation starts to decrease in 2000 , with continuous decline of $5 \%$ to $10 \%$ at middle latitudes in the both Northern and Southern Hemispheres.
\end{abstract}

\section{Introduction}

The ozone hole in the Southern Hemisphere (Farman et al., 1985) and the ozone depletion in the Northern Hemisphere led to the promulgation of the Montreal Protocol. In accordance with the Montreal Protocol and its Amendments and Adjustments (MPA), concentrations of halogen-containing gases that deplete the ozone layer are projected to decrease considerably. Extensive model experiments (WMO, 2011; SPARC CCMVal, 2010) have shown that the atmospheric ozone column will increase reaching its values typical of the late 1970s in the middle of 21 st century.

There were several attempts to estimate the effectiveness of the MPA. The first estimates were made with an array of two-dimensional models (e.g., Prather et al., 1996; World Meteorological Organization (WMO), 1999). Later on Egorova et al. (2001) exploited atmospheric chemicaltransport model (ACTM) to assess the effect of the MPA. They carried out two model simulations with the University of Illinois at Urbana-Champaign (UIUC) ACTM, one with the actual values of the chlorofluorocarbon (CFC) concentrations and another with the CFC concentrations prescribed according to the "No-Protocol" (H1) scenario (WMO, 1999) wherein there is about a $3 \%$ annual growth of the tropospheric CFC's emission. They showed that the MPA began to affect the ozone layer noticeably in 1996/1997. For the Northern Hemisphere the influence of the reduced active chlorine depends on the meteorological situation and is more conspicuous for colder stratospheric winters. For the Southern Hemisphere, the effect mainly depends on the amount of chlorine loading. The quantitative results that were obtained in this study are not accurate because the temperature and circulation fields were prescribed in the model. Ever since, the numerical models were greatly developed and 
presently the studies devoted to this issue exploit chemistryclimate models (CCM), which are able to simulate the interactions between chemistry and thermo-dynamical processes. Recently two papers were published which explore the effectiveness of MPA using state-of-the art CCMs. Morgenstern et al. (2008) applied the UK Chemistry and Aerosol (UKCA) chemistry-climate model to study the effects of high chlorine loading on ozone and climate. They compare two time slice simulations with the total chlorine loading of 9 ppbv, which could have happened by 2030 without MPA limitations, and $3.5 \mathrm{ppbv}$ (year-2000 chlorine loading) according to the scenario of WMO (2007). The analysis of the results is focused on ozone changes and their climate impact. They concluded that the MPA has provided an enormous benefit for the stability of the ozone layer and surface climate. Newman et al. (2009) employed the Goddard Earth Observing System (GEOS) chemistry-climate model to explore the ozone distribution that might have occurred without ODS regulations. They carried out transient simulation from 1974 to 2065 using $3 \%$ per year rate of equivalent effective chlorine growth and IPCC (2001) Alb scenario for other greenhouse gases. They obtained very large ozone losses by the end of the simulated time interval and a year-round ozone hole in the Southern Hemisphere. Furthermore, they also calculated the spectral changes in surface UV irradiance and showed that the obtained decreases in stratospheric ozone subsequently led to increases in erythemal irradiance for a cloud-free atmosphere. In particular they obtained a threefold increase of the surface erythemal radiation in the summer of northern latitudes by 2065 .

While our paper was under revision, two more articles devoted to the MPA issue have appeared. Garcia et al. (2012) used a coupled AOCCM to study MPA effects and pointed out that their results with using a coupled deep ocean are consistent with the results obtained with CCM without a deep ocean by the Egorova et al. (2012). Another paper by Wu et al. (2012) is now in press and focus specifically on the hydrological impacts of the Montreal Protocol.

The above described research papers have shown that substantial ozone depletion could occur in the absence of the Montreal Protocol and its Amendments. However WMO (Ch.5, 2011) pointed out that in Morgenstern et al. (2008) and Newman et al. (2009) certain processes are absent that potentially could influence the results. In the GEOSCCM used by Newman et al. (2009) tropospheric ozone is prescribed, therefore, their model does not have tropospheric chemistry at all and tropospheric ozone may respond only to the transport changes caused by the introduced chemical perturbations. Morgenstern et al. (2008) used fixed photolysis rates in the troposphere, which means that tropospheric ozone does not react to UV changes caused by stratospheric ozone depletion. The absence of realistic tropospheric chemistry in the both models does not allow taking into account neither possible increase of the tropospheric ozone due to the enhanced level of tropospheric UV irradiance nor its destruc- tion by halogens. Moreover, Morgenstern et al. (2008) did not simulate the evolution of the ozone layer and did not consider the changes in radiative forcing from ODS. Newman et al. (2009) demonstrated dramatic ozone depletion in the future and substantial alteration of the entire circulation regime of the stratosphere, which needs to be confirmed using independent models. Therefore, new efforts to assess the MPA effectiveness were made in the context of the CCM validation campaign CCMVal-2 (SPARC CCMVal, 2011). In the framework of this campaign the transient simulations with reference and world avoided scenarios of ODS concentrations similar to Newman et al. (2009) were performed with several CCMs covering 1960-2100, but so far those simulations have not been analysed. In our simulations we applied CCM SOCOL which includes basic (without VOCs) tropospheric chemistry and on-line calculations of the photolysis rates, therefore, the changes of the tropospheric ozone could be substantially different from Morgenstern et al. (2008) and Newman et al. (2009). Also our simulations cover the whole 21 st century (end of the simulation in 2100) whereas Morgenstern et al. (2008) performed time slice experiments and Newman et al. (2009) terminated their simulations in 2065.

Here we describe the performed reference (MPA) and scenario (noMPA) experiments, and analyse the results that were obtained with CCM SOCOL (Schraner et al., 2008) within the framework of the CCMVal-2 inter-comparison (SPARC CCMVal, 2011). We estimate the effectiveness of the MPA on ozone, temperature, stratospheric circulation, surface temperature, precipitation and total ozone. The projection of the surface UV radiation in the future and the influence of climate change on them are an important issue now (e.g., Hegglin and Shepherd, 2009). We also investigate the influence of the Montreal Protocol on erythemally weighted UV irradiance $\left(E_{\text {ery }}\right)$ for the period 1960-2100 in both cloud-free and cloudy atmospheres. The total ozone column is the main influencing parameter on the amount of UV radiation, which reaches the surface of the Earth (e.g., Tourpali et al., 2009). Other factors are ozone profile (e.g., McKenzie et al., 2003), albedo, aerosols and clouds. Any trend of these factors will influence future UV levels. Meehl et al. (2007) suggest a decrease in cloud cover of $4 \%$ by the end of the 21 st century in most of the low and middle latitudes counteracting the recovery of the ozone and leading to higher UV irradiance. The evolution of the aerosols in the future is highly uncertain and has not been included in our CCM runs. $E_{\text {ery }}$ is used as a metric to characterise future UV levels. As novelty, this UV study evaluates the influence of the Montreal Protocol on UV radiation reaching the surface of the Earth compared to the situation if the Montreal Protocol had not been agreed upon. A similar investigation was performed by Newman and McKenzie (2011) for clear sky UV irradiances. They also found significantly enhanced UV levels under the "No Montreal Protocol Scenario". However, their study did not take into account changes in neither albedo nor cloud 
cover, which have important effects on surface UV irradiances.

Section 2 describes the CCM SOCOL and the performed simulations. Section 3 describes the evolution of the ozone, temperature, total ozone of the atmosphere as well as circulation of the stratosphere, surface temperature and precipitation. Section 4 provides the estimations of the erythemal irradiance. Finally, we give some concluding remarks.

\section{Description of the model and numerical experiments}

\subsection{Model description}

CCM SOCOL is a three-dimensional global chemistryclimate model. It was developed at the PhysicalMeteorological Observatory (Davos, Switzerland) in collaboration with ETH (Zürich, Switzerland) and Voeikov Main Geophysical Observatory (St. Petersburg, Russia) (Egorova et al., 2005). The CCM SOCOL is a combination of the middle atmosphere version of the European Centre/Hamburg Model 4 General Circulation Model (MA-ECHAM4) (Manzini et al., 1997) with a modified version of the University of Illinois at Urbana-Champaign three-dimensional CTM Model for the Evaluation of Ozone Trends (MEZON) (Egorova et al., 2003).

The horizontal resolution of SOCOL is $3.75^{\circ} \times 3.75^{\circ}$. Vertically, this model is divided into 39 levels in a hybrid sigma/pressure coordinate system and extends from the surface to $0.01 \mathrm{hPa}(\sim 80 \mathrm{~km})$. The CTM MEZON calculates the distributions of concentrations of 45 trace gases from the major atmospheric groups, which are determined by 118 gas phase reactions, 33 photolytic reactions, and 16 heterogeneous reactions. The photolysis rates are calculated on-line using look-up-table approach described by Rozanov et al. (1999). The transport of trace gases in the CTM MEZON is calculated using the advection scheme (Zubov et al., 1999). The time step for the dynamic core of the MAECHAM4 model is $15 \mathrm{~min}$. Parameters of physical processes as well as photochemical processes are calculated every $2 \mathrm{~h}$. The model parts of the CCM SOCOL (MEZON and MAECHAM4) exchange data on the fields of major dynamical variables and radiatively active gases every $2 \mathrm{~h}$. Concentrations of ozone, methane, nitrous oxide, chlorofluorocarbons and stratospheric water vapour are transferred from MEZON to MA-ECHAM4, and three-dimensional distributions of temperature, water vapour concentration and zonal, meridional and vertical components of wind velocity are transferred from MA-ECHAM4 to MEZON. Thus, the interactive character of the CCM SOCOL makes it possible to correctly include the main feedbacks between dynamical, advective, photochemical and radiative processes. The original version of SOCOL is described in detail in Egorova et al. (2005).
The CCM SOCOL extensively participates in the international Chemistry-Climate Model Validation Activity (CCMVal) of the Stratospheric Processes and Their Role in Climate (SPARC) programme on chemistry-climate model intercomparison and testing (Eyring et al., 2006, 2007, 2010). A preliminary intercomparison of the results from SOCOL test runs with analogous results from other models and with ground-based and satellite observations showed a good overall performance of SOCOL. A number of model deficiencies in describing the global transport of chemical species and heterogeneous processes in the Polar region have been found (Eyring et al., 2007). In the improved model version SOCOL 2.0 (Schraner et al., 2008), the transport of the major families of the chlorine, nitrogen and hydrogen groups was included in the transport scheme, as result of which, in particular, the model managed to significantly improve the characteristics of the numerical transport of odd chlorine in the polar stratosphere. A more adequate scheme of mass correction in the horizontal semi-Lagrangian part of the numerical transport scheme was additionally used for calculating ozone transport, which in its formulation is not conservative. An updated thermodynamic parameterisation for polar stratospheric cloud formation was also included in the model. The new model version more correctly describes the distribution, transport and transformation of the atmospheric halogen-containing species and ozone in the middle and high latitudes in the stratosphere of both hemispheres (Schraner et al., 2008). The improved model version (SOCOL 2.0), with eleven other modern CCMs, has also been tested in the analysis of the simulation of Southern Hemisphere ozone evolution in the last $25 \mathrm{yr}$ of the 20th century (Karpechko et al., 2010).

\subsection{Description of the numerical experiments}

To assess the effectiveness of the Montreal Protocol and its Amendments, we carried out two $140 \mathrm{yr}$ long transient simulations with CCM SOCOL v.2.0 (Schraner et al., 2008) spanning 1960-2100 and driven by the prescribed evolution of the Sea Surface Temperature (SST), Sea Ice (SI), Greenhouse Gases (GHG), Ozone Depleting Substances (ODS) and source of $\mathrm{CO}$ and NOx.

In the reference simulation GHG $\left(\mathrm{N}_{2} \mathrm{O}, \mathrm{CH}_{4}\right.$, and $\left.\mathrm{CO}_{2}\right)$ are taken from the IPCC (2001) "A1B" scenario. We use simulated SSTs and SIs for the entire period from ECHAM5MPIOM experiments (Roeckner et al., 2003, 2004). Surface mixing ratios of ODS are based on the halogen scenario A1 from WMO (2007) and on adjusted HCFCs scenario of nearly a full phase out in 2030. In the stratosphere background, non-volcanic sulfate aerosol loading is assumed, while the tropospheric aerosols are not considered. More detailed description of the reference simulation and used anthropogenic forcing can be found in Eyring et al. (2010) and Morgenstern et al. (2010a). 

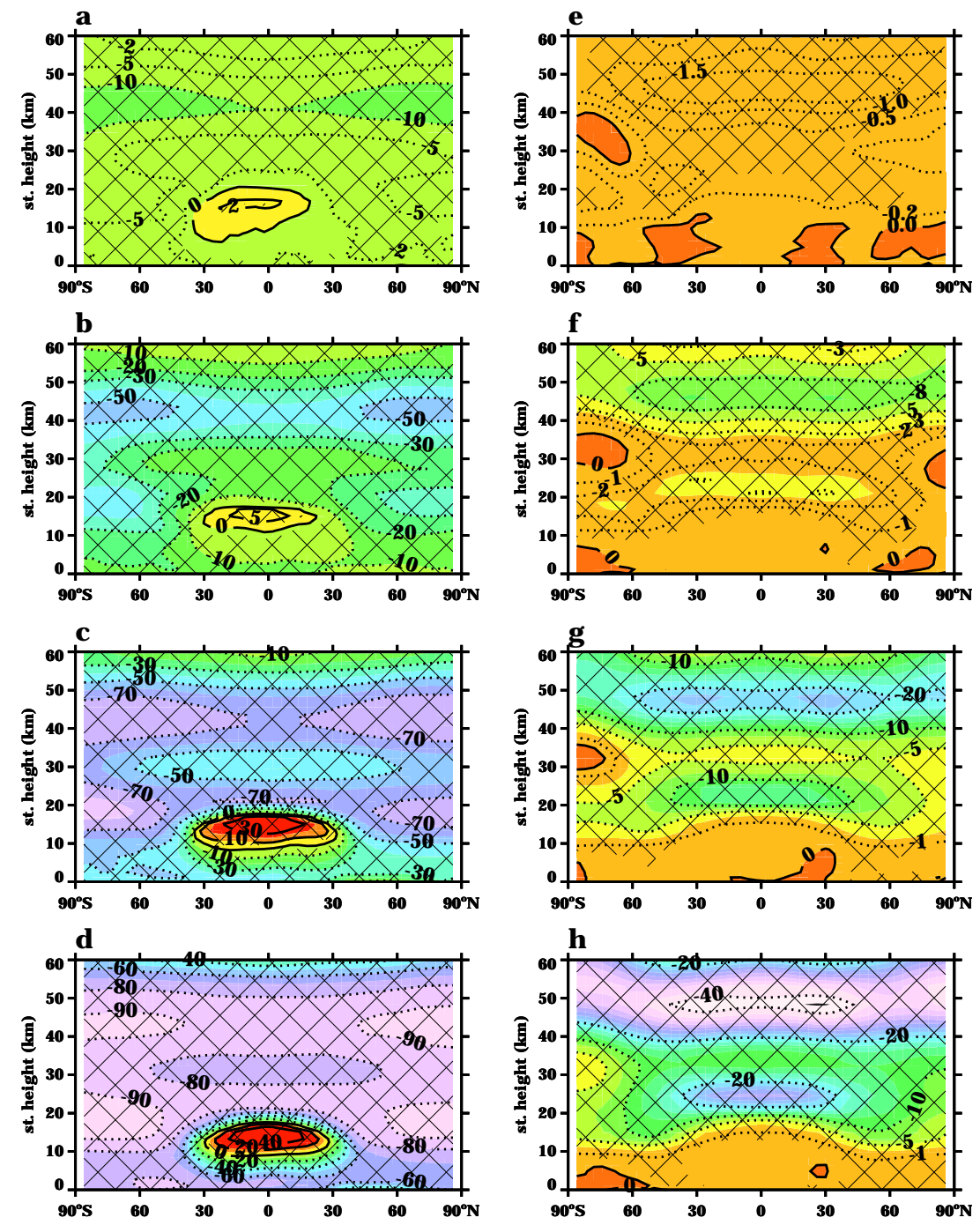

Fig. 1. Zonal mean annual mean ozone (a, b, $, \mathbf{c}, \mathbf{d})$ (in $\%$ ) and temperature $(\mathbf{e}, \mathbf{f}, \mathbf{g}, \mathbf{h})$ (in K) changes due to absence of the MPA regulations for decadal averaged time periods 1987-2012, 2025-2035, 2055-2065 and 2090-2100. Hatching represent the areas where the statistical significance exceed $95 \%$ level.

For the second scenario simulation (noMPA), which was designed to estimate the role of the Montreal Protocol, we applied ODS from the so called world avoided scenario proposed by Velders et al. (2007) where ODS is increasing by $\sim 3 \%$ per year due to the absence of the limitation introduced by the MPA. The scenario starts in 1987 and shows what would have happened without any further national regulations, international agreements, or public actions. It is a transient simulation similar to the reference simulation, but with halogen loading evolution taken from the world avoided scenario throughout the simulation, whereas GHGs and SSTs/SIs are the same as in the reference simulation.

\section{Results}

\subsection{Zonal mean ozone and temperature}

Figure 1 presents zonal mean distribution of annual mean ozone mixing ratio (in \%) and temperature (in $\mathrm{K}$ ) as differences between the scenario (noMPA) and reference (MPA) simulations for decadal averages 1987-2012 (a, e), 20252035 (b, f), 2055-2065 (c, g) and 2090-2100 (d, h). In our simulation the absence of the MPA leads to the ozone decrease everywhere except at $10-20 \mathrm{~km}$ in the tropical area, where we obtain $5 \%$ ozone increase for the near future (2025-2035) more than $30 \%$ for the 2055-2065 and more than $60 \%$, for the distant future (2090-2100). The latter effect is the result of the downward shift of the ozone net production caused by strong ozone depletion in the upper 
and middle stratosphere followed by an increase of the oxygen photolysis rates in the lower stratosphere and enhanced level of active halogens. According to our calculations for the present time without the MPA, we would have 10-20\% less ozone in the upper stratosphere as we have it currently and 6-8\% less ozone in the lower stratosphere in the polar areas of the Southern and Northern Hemispheres. In comparison with simulations by Morgenstern el al. (2008) for 2030, we have $10 \%$ more ozone decrease in the upper stratosphere and good agreement in the polar areas of the lower stratosphere. The area of tropical ozone increase is also in a good quantitative agreement with Morgenstern el al. (2008) results, but the location is somewhat lower, at $15 \mathrm{~km}$. The ozone decrease in the troposphere is slightly smaller than it obtained by Morgenstern el al. (2008) due to additional tropospheric ozone production by the increased level of UV radiation, which was not included in their model.

As seen from Fig. 1 (e, f, and g, h) the ozone changes lead to concomitant changes in temperature. The upper stratosphere cools down by $1.5 \mathrm{~K}$ in $1987-2012$ and up to $40 \mathrm{~K}$ in 2090-2100. The comparison with Morgenstern et al. (2008) results shows that in the upper stratosphere we obtain more pronounced cooling, which is expected because the sensitivity of their radiation code to the ozone changes is slightly smaller than in our model (Forster et al., 2011). In the lower stratosphere our results show $-3 \mathrm{~K}$ cooling, while Morgenstern et al. (2008) have got only $0.5 \mathrm{~K}$ temperature decrease. Part of this difference can be explained by the cooling from halogen increase which was not considered by Morgenstern et al. (2008). The cooling patterns in the polar stratosphere also look quite different. Results of CCM SOCOL do not show a pronounced dipole structure. It means that by 2030, we have not obtained substantial changes of circulation fields. In comparison with the Newman et al. (2009) results, we see good agreement in the middle stratosphere, where the ozone loss reaches $40-60 \%$ and in the upper stratosphere where both models show $70 \%$ ozone decrease (see Fig. 1e). In the polar areas of the lower stratosphere, we obtain 70$80 \%$ ozone decrease, which is only about $10 \%$ less than obtained by Newman et al. (2009). The most pronounced disagreements appear in the troposphere and tropical stratosphere, where the simulated ozone increase exceeds $30 \%$ in our model while Newman et al. (2009) obtained only about $10 \%$. The disagreement in the tropical stratosphere can be explained by more intensive heterogeneous halogen activation caused by stratospheric cloud appearance in the model applied by Newman et al. (2009). In the troposphere the simulated ozone destruction by more than $30 \%$ is almost completely absent in the Newman et al. (2009) results because their model does not include tropospheric chemistry.

For the temperature changes in 2055-2065 (Fig. 1g) our simulation results show cooling of about $20 \mathrm{~K}$ in the upper stratosphere, $5 \mathrm{~K}$ in the middle stratosphere and $10 \mathrm{~K}$ in the tropical lower stratosphere and slight warming around $35 \mathrm{~km}$ over the southern high latitudes. The obtained temperature
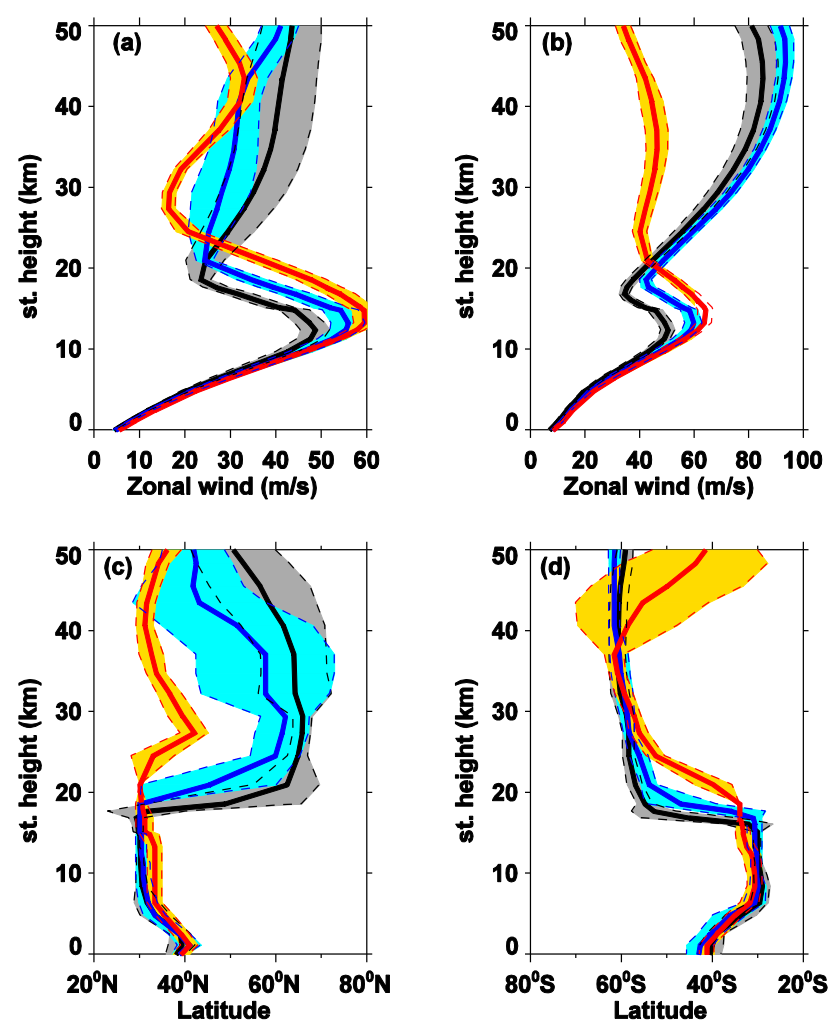

Fig. 2. Zonal wind speed (a, b) and latitude of the jet maxima (c, d) for the boreal winter in the Northern Hemisphere (a, c) and austral winter in the Southern Hemisphere (b, d). The results are for the years 1987-2012 (black lines) and 2090-2100 (blue lines) of the reference run and for the years 2090-2100 of the noMPA run (red lines). The shading indicates standard deviations.

response is in a good agreement with the results obtained by Newman et al. (2009).

\subsection{Circulation in the stratosphere}

The changes in the temperature described in the previous section affect stratospheric circulation pattern. The changes of the winter time stratospheric jets in the Northern $(\mathrm{NH})$ and Southern (SH) Hemispheres are illustrated in Fig. 2 using the zonal wind speed and latitude of the jet maxima as it was done in Butchart et al. (2011). The changes of the subtropical jets in the $\mathrm{NH}$ and $\mathrm{SH}$ are similar. As it was pointed out previously (e.g., Shepherd and McLandress, 2011), the impact of the greenhouse gases strengthens the jets and slightly extends their upper flanks in vertical direction. These changes are more pronounced for the noMPA case due to additional cooling in the extra-tropical lower stratosphere, however, the central latitudes and the persistence of the subtropical jets remain practically unchanged. More dramatic changes appear over the high latitudes. In the $\mathrm{NH}$ some deceleration of the jet is visible between 25 and $45 \mathrm{~km}$, while the latitude of the jet maxima is shifted by about $20^{\circ}$ toward the equator. The 

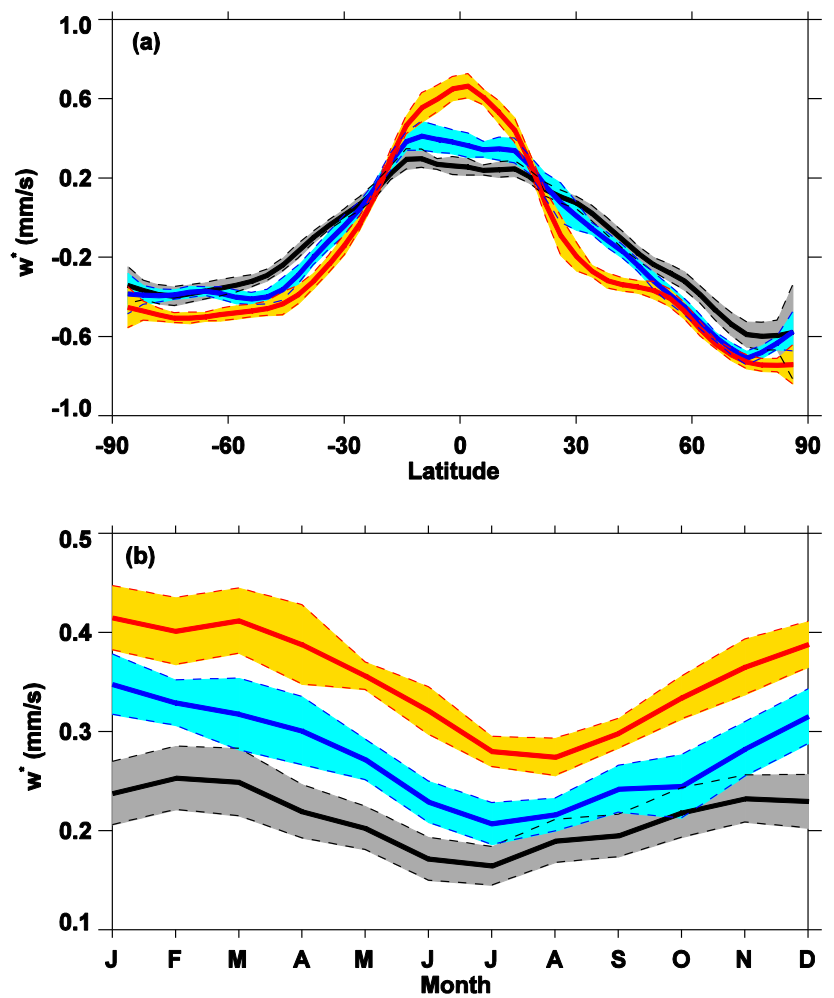

Fig. 3. Annual mean (a) and monthly mean (b) residual vertical velocities at $50 \mathrm{hPa}$ averaged over $30^{\circ} \mathrm{S}-30^{\circ} \mathrm{N}$. The results are for the years 1987-2012 (black lines) and 2090-2100 (blue lines) of the reference run and for the years 2090-2100 of the noMPA run (red lines). The shading indicates standard deviations.

opposite effects are observed in the SH where the latitude of the jet core only slightly moves equatorward in the lower and upper stratosphere, while the jet strength reduces by up to $40 \mathrm{~m} \mathrm{~s}^{-1}$. These changes are explained by the strong cooling in the equatorial stratosphere followed by the decrease of the equator-to-pole temperature gradient. It is interesting to note that the interannual variability of the $\mathrm{NH}$ polar night jet is substantially smaller for the noMPA run. The changes of the wind distribution between the experiments affect the wavedriven Brewer-Dobson circulation (BDC). The residual vertical velocities $\left(w^{*}\right)$ are presented in Fig. 3. The annual mean $w^{*}$ (Fig. 3a) show significant (almost 100\%) increase in the tropical area in the noMPA run and consistent increase of the down welling between $30^{\circ}$ and $60^{\circ}$ in the $\mathrm{NH}$ and from $50^{\circ}$ and $70^{\circ}$ in the SH. The seasonal cycle of the residual vertical velocities in the tropical lower stratosphere (see Fig. 3b) shows that the intensification of the tropical upwelling occurs during all months, but reaches its maxima during boreal winter. Similar but less pronounced features are also visible from the comparison of the future and present day BDC in the reference run. The changes of the BDC consist of acceleration and vertical shift of the subtropical jets and overall weakening and displacement of the polar vortices.

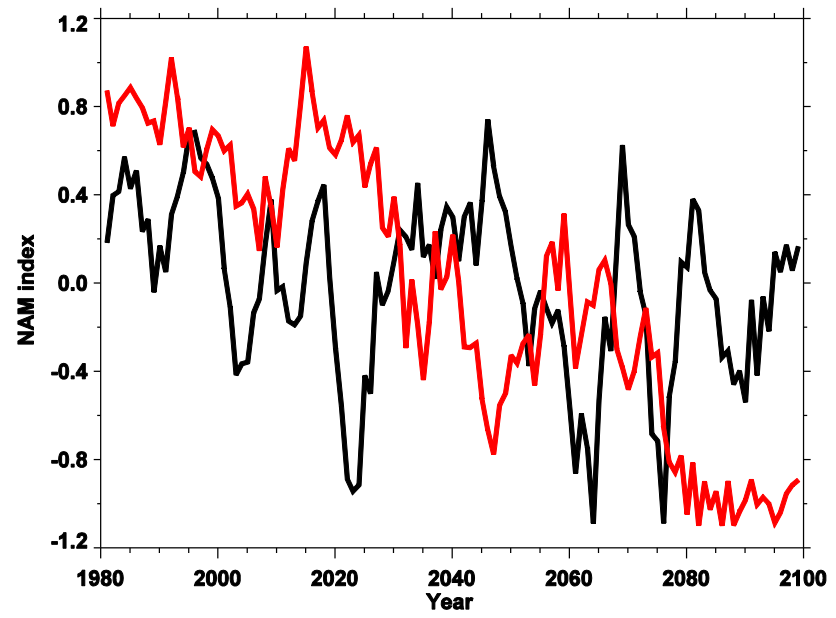

Fig. 4. NAM indices, scaled to unit standard deviation, obtained from the geopotential field at $50 \mathrm{hPa}$ of the reference (black line) and noMPA (red line) runs for the DJF season over the Northern Hemisphere. The indices have been smoothed with $11 \mathrm{yr}$ boxcar filters.

It is also of interest to analyse the changes of the Northern and Southern Annular Modes (NAM and SAM) in the stratosphere because these modes can be influenced by the changes in the stratosphere induced by substantial ozone depletion in the noMPA run. Their role in connecting the stratosphere and troposphere is known and may help to explain the changes of the surface temperature discussed in Sect. 3.4. We calculate seasonal NAM and SAM indices for the reference and noMPA run from monthly mean geopotential heights at $50 \mathrm{hPa}$ level using the approach described by Morgenstern et al. (2010b). The evolution of the wintertime NAM index is illustrated in Fig. 4. It was already shown by Morgenstern et al. (2010b) that for the CCM SOCOL the long-term variability in the reference run is rather small, therefore, similar behaviour of the calculated NAM index confirms the correct application of the applied approach. The NAM index for the noMPA run is different showing persistent decrease. It means that during the last $20 \mathrm{yr}$ of the simulation, when the ozone depletion is the most pronounced the negative NAM phase dominates. This effect is reflected in overall weakening and dilution of the Northern polar vortex in agreement with the above shown changes of the vortices and BDC. Any significant difference of the winter time SAM indices (not shown) is not observed.

\subsection{Total ozone}

Figure 5 illustrates the time evolution of the monthly mean total ozone saved by the MPA in percent from 2000 to 2011 (a) and from 2055 to 2065 (b). It is clearly seen that the Polar Regions are the most sensitive to the reduction in the active halogen burden. We find that the MPA has already saved $10-30 \%$ of the present-day total ozone in the Northern and 
Southern Hemispheres. In the tropical and extra tropical latitudes the saved ozone amount exceeds 5\%. In 2055-2065 the MPA prevent about $50 \%$ of total ozone destruction in the tropical and extra-tropical latitudes and more than 70-80\% in the high latitudes of the Northern and Southern Hemispheres.

Figure 6 demonstrates that the ozone destruction by increased stratospheric halogen loading is also essential for the global and annual mean total column ozone. The continuous increase of stratospheric halogens leads to almost complete $(\sim 80 \%)$ global ozone loss at the end of 21 st century. The global mean total ozone loss calculated as the difference between noMPA and MPA simulations is already rather dramatic in 2030 reaching $\sim 80$ D.U. The geographical distribution of the annual mean total ozone loss for this particular year is illustrated in Fig. 7. As expected, the most pronounced (30-40\%) total ozone loss occurs over the cold polar areas; however, even in the tropics the ozone loss can exceed $15 \%$. Over Europe and North America the total ozone loss is about $20 \%$, which would lead to an increase of dangerous erythemal irradiance by $\sim 20-30 \%$. The obtained results are in reasonable agreement with the total ozone loss estimates published by Newman et al. (2009).

The geographical distribution of the annual-mean total ozone destruction prevented by the MPA is presented in Fig. 8. Model results for 2009 show maximum benefit for the Northern Hemisphere due to the MPA implementation, which is more than $25 \%$. For Northern Europe the benefits are about $8-15 \%$. In the Southern Hemisphere the largest benefit during the last $10 \mathrm{yr}$ was obtained in 2003 , which is reaching more than $30 \%$.

Figures $5 \mathrm{a}$ and 8 also show that for the present-day total ozone the effect of the MPA limitations on man-made halogen containing species depends not only on the amount of chlorine loading, but also on the meteorological conditions and is more pronounced for a colder stratospheric winter. These results support previous estimations presented by Egorova et al. (2001).

\subsection{Surface air temperature and precipitation changes}

Large ozone loss leads to substantial and statistically significant changes in the surface air temperature over the continents as illustrated in Fig. 9. The model results reveal pronounced surface warming of up to $1 \mathrm{~K}$ over the South Pole and Southern China. Less intensive and not statistically significant warm anomalies of about $0.5 \mathrm{~K}$ also appear over Greenland, Canada, north of Australia, Brazil and Paraguay. Very pronounced cooling spots (up to $-2.5 \mathrm{~K}$ ) appear over Europe, Russia, Northern Asia (Kazakhstan and Mongolia) and Argentina. The geographical distribution of the surface air temperature changes resembles the pattern typical for the negative NAM phase in agreement with results presented in the Sect. 3.2. Over the oceans the surface air temperature changes are not large because the sea surface temperatures

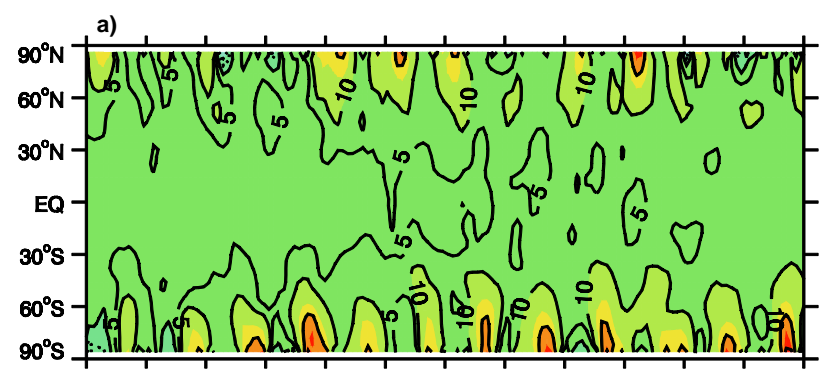

2000200120022003200420052006200720082009201020112012

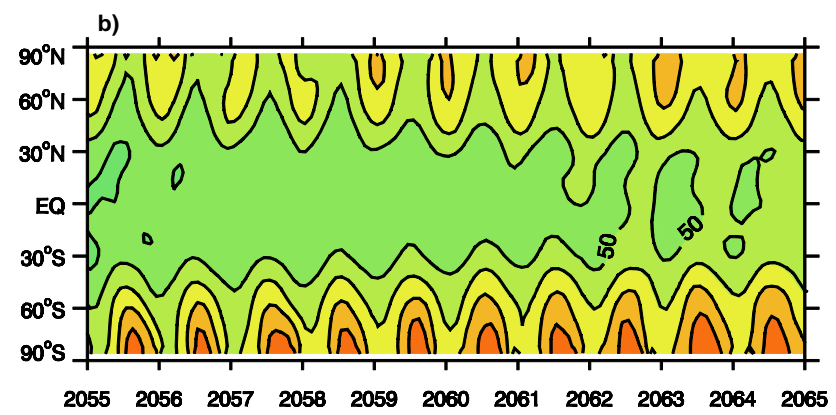

Fig. 5. Simulated year-to-year evolution of the total ozone destruction prevented by the MPA. The values for isolines in percent are for (a) 2000-2012: 5, 10, 30; for (b) 2055-2065: 50, 60, 70, 80.

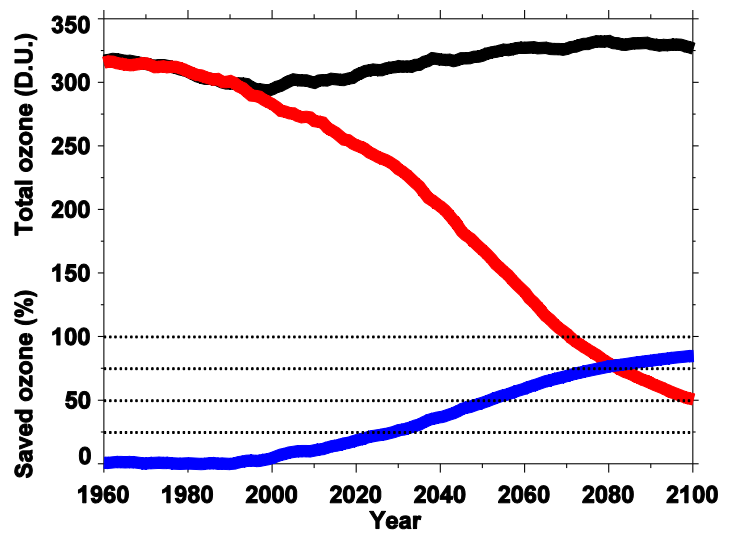

Fig. 6. Time evolution of the global and annual mean total ozone for the reference (black) and no Montreal protocol (red) simulations. Total ozone saved by the Montreal Protocol limitations (\%) is represented by the blue line.

are the same in both scenario and reference run. In comparison with historical records of surface air temperature evolution, the obtained large anomalies over the land imply that in the world without the MPA considerable climate impact is possible.

By the end of the 21st century, our model simulates some changes in the precipitation intensity shown in Fig. 10. The precipitation increases by up to $25 \%$ mostly over the middle latitudes of the both hemispheres with the maximum over the Central Asia and Tropical Eastern Pacific. 


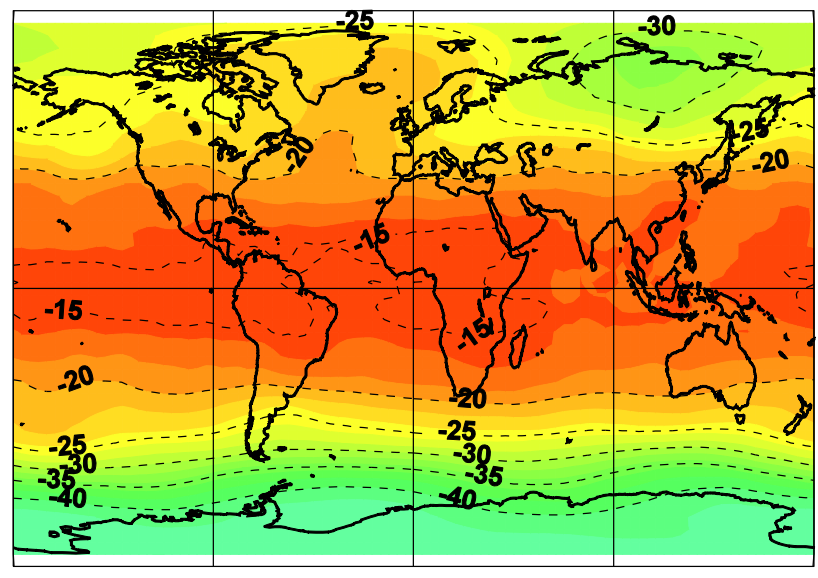

Fig. 7. The geographical distribution of the annual mean total ozone loss $(\%)$ calculated as the relative deviation of noMPA from MPA results for the year 2030 .
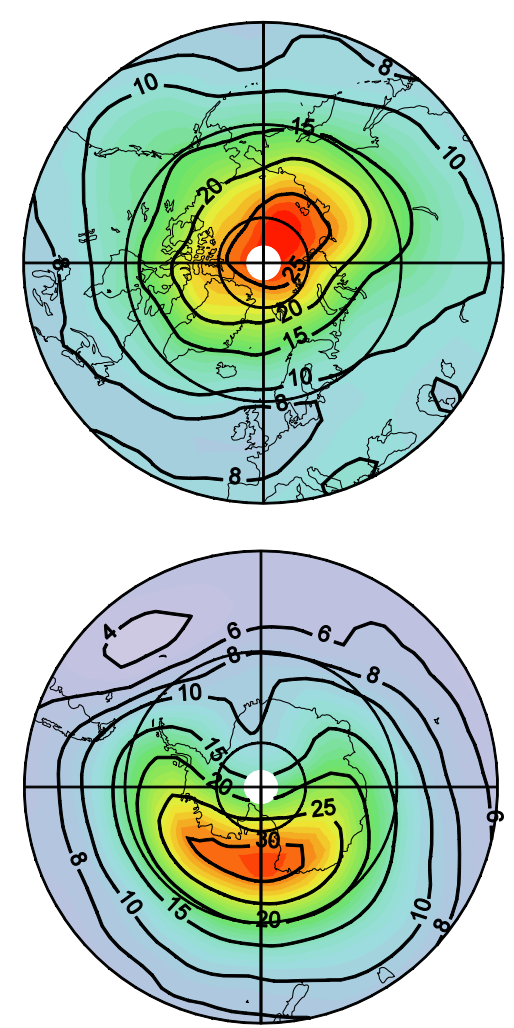

Fig. 8. Geographical distribution of the annual-mean total ozone destruction prevented by the MPA for the Northern Hemisphere in 2009 (upper panel) and for Southern Hemisphere in 2003 (lower panel). The values for isolines in percent are: 4, 6, 8, 10, 15, 20, 25.

\section{Erythemal UV Irradiance estimations}

Clear-sky surface UV irradiances have been calculated with the radiative transfer model UVSpec from libRadtran (Mayer and Kylling, 2005) using the following output parameters

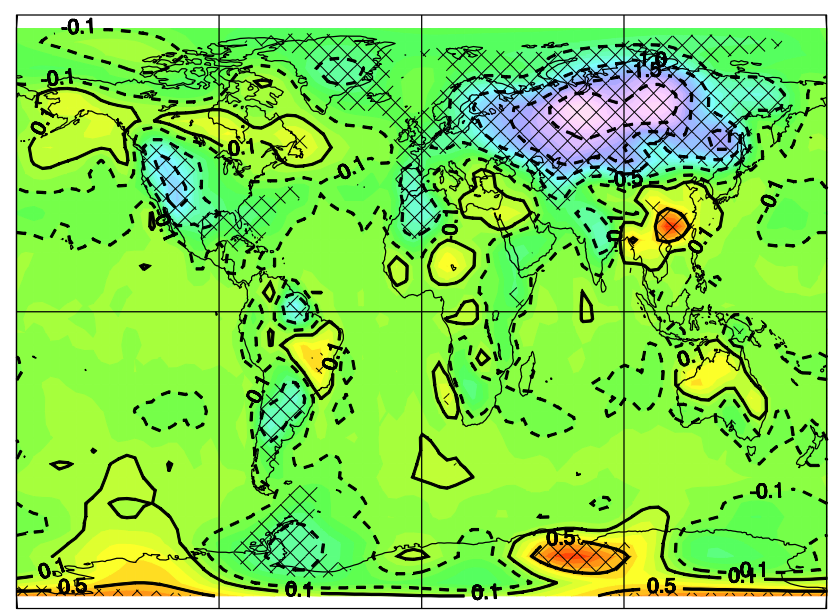

Fig. 9. Difference of the surface temperature between scenario and reference simulations averaged over the time period 2090-2100 (annual mean in K). Hatching represent the areas where the statistical significance exceed $95 \%$ level.

from the CCM SOCOL: total column ozone, ozone profile, temperature profile, surface albedo. In this study, the standard plane-parallel disort algorithm (Stamnes et al., 1988) has been applied using 4 streams, which give an error of less than $0.5 \%$ for solar zenith angles (SZA) smaller than $75^{\circ}$ and less than $1.5 \%$ for larger SZA in comparison with the calculations using 16 streams. For all calculations the default aerosol profile of UVSPEC was used (Shettle, 1990). The mean elevation of every grid point as given by SOCOL has been used to set the surface height. For every grid point the global, diffuse and direct UV irradiance spectrum have been calculated for the 15th of each month and local noon, to obtain an estimate of the maximum UV level. For this study, only the global irradiances have been used after the convolution with the erythemal action spectrum to estimate the impact of the UV levels on the human population; other weightings could be used depending on the application. The future changes in cloud cover estimated by the CCM SOCOL have been converted to Cloud Modification Factors in the UV range using a formula developed by Den Outer et al. (2005). These correction factors were then multiplied with the modelled clear-sky UV irradiances to obtain erythemal UV irradiances under cloudy conditions.

\subsection{No Montreal Protocol scenario}

Under the assumption that the Montreal Protocol was not implemented, the surface UV irradiances undergo dramatic increases during the 21st century and illustrated in Fig. 11. Even though the changes are modulated by latitude and season, erythemal UV irradiances increase by factors of 4 to 16 between the 1970s and 2100. As discussed in Newman and McKenzie (2011), the impact of these high UV levels on the whole biosphere would have significant negative 


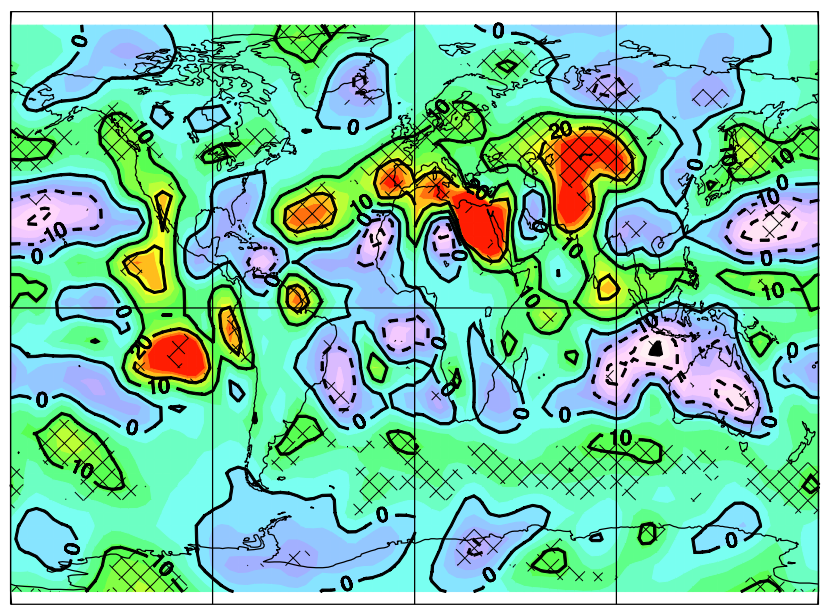

Fig. 10. Precipitation difference $\left(\mathrm{mm} \mathrm{s}^{-1}\right)$ between scenario and reference simulations averaged over time period 2090-2100 (annual mean). Hatching represent the areas where the statistical significance exceed $95 \%$ level.

consequences, with UV indices in the summer season exceeding the current maximal UV levels of 25 in the most populated areas.

Figure 12 displays the relative changes of $E_{\text {ery }}$ in September for five latitudinal bands relative to the 1970-1979 average. The changes are largest over the southern high latitudes, with increases of more than a factor 16 by the end of this century due to the dramatic ozone losses over the Antarctic Peninsula. The relative increases over the middle and low latitudes are between 4 and 8 times the values found in the pre-Montreal Protocol era, leading to UV Index values in excess of 50, which are more than double the highest values found currently on Earth.

These UV increases can be mainly attributed to the corresponding decrease in atmospheric ozone due to the continuous emission of ozone depleting substances in the atmosphere, as described in the previous sections. Changes in the other parameters, such as surface albedo or clouds have a negligible influence.

\subsection{Montreal Protocol scenario}

The CCM SOCOL reference run, implementing the Montreal Protocol limitations and the following amendments, was used to infer the most plausible future UV changes to be expected in the 21 st century. Figure 13 shows the expected changes of erythemal UV irradiances for five latitudinal bands, relative to the reference years. UV radiation increases slightly in the last decades of the previous century corresponding to the observed ozone decreases. In line with the implementation of the Montreal Protocol, UV radiation starts to decrease around 2000, with continuous decreases of $5 \%$ to $10 \%$ at middle latitudes in the Northern and Southern Hemispheres. UV radiation actually decreases to lower
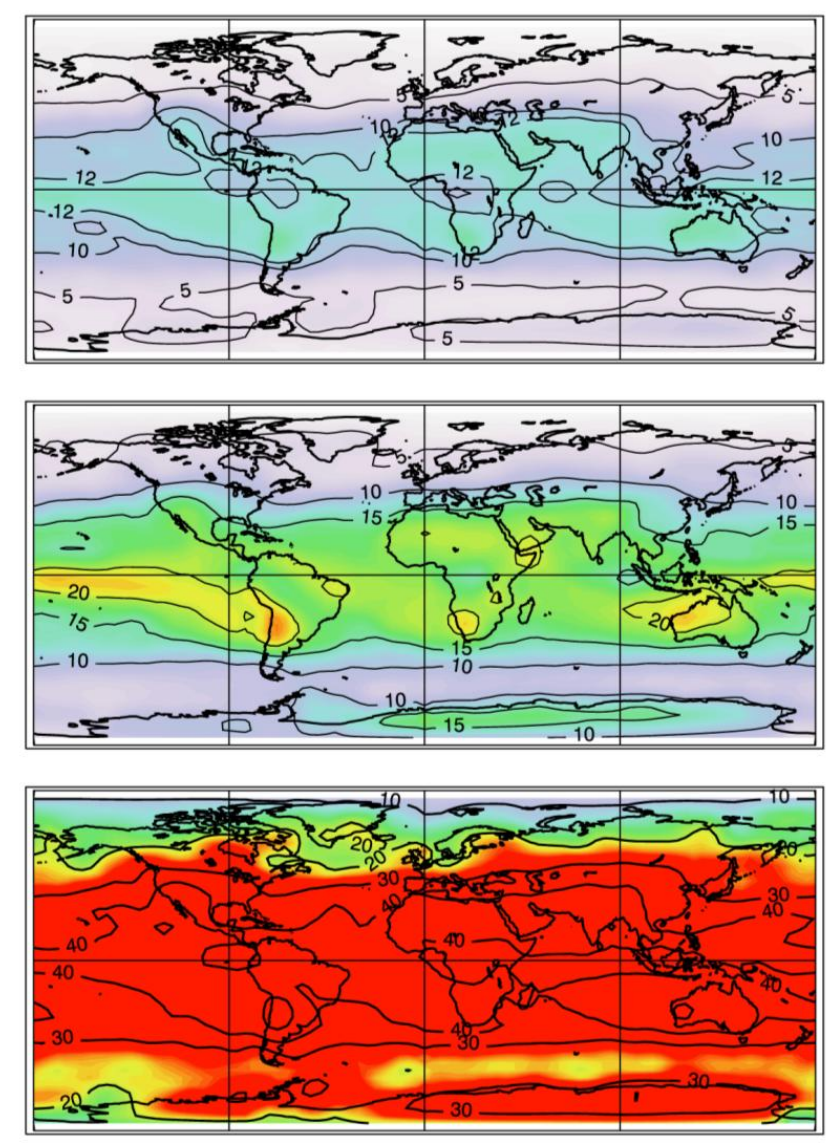

Fig. 11. Maximal UV indices calculated in the years 2010, 2050 and 2090 in noMPA case. The colour scale was limited to a UV Index of 25 to reflect the current (2010) maximum UV levels observed in the South American Andes. The contour lines have no upper limit and extend from UV index 0 to 40 in steps of 10.

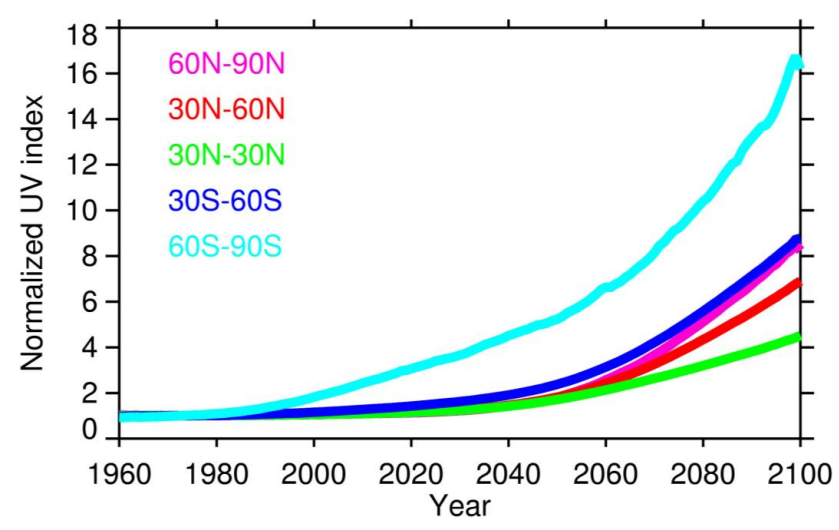

Fig. 12. Changes of erythemal weighted UV irradiances for five latitudinal bands $90^{\circ} \mathrm{N}-60^{\circ} \mathrm{N}$ (blue), $60^{\circ} \mathrm{N}-30^{\circ} \mathrm{N}$ (green), $30^{\circ} \mathrm{N}-$ $30^{\circ} \mathrm{S}$ (red), $30^{\circ} \mathrm{S}-60^{\circ} \mathrm{S}$ (light blue) and $60^{\circ} \mathrm{S}-90^{\circ} \mathrm{S}$ (violet) in September relative to the 1970-1979 average for the noMPA scenario. 


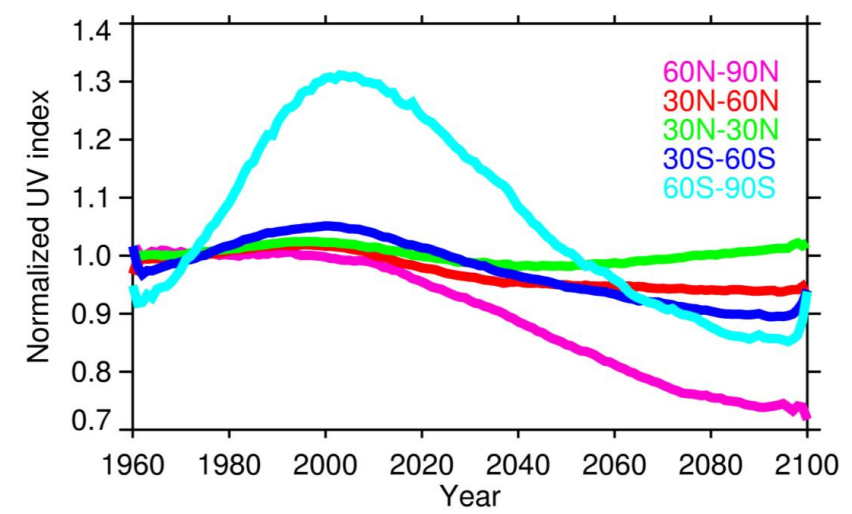

Fig. 13. Changes of erythemal weighted UV irradiances for five latitudinal bands $90^{\circ} \mathrm{N}-60^{\circ} \mathrm{N}$ (blue), $60 \mathrm{~N}-30 \mathrm{~N}$ (green), $30^{\circ} \mathrm{N}-30^{\circ} \mathrm{S}$ (red), $30^{\circ} \mathrm{S}-60^{\circ} \mathrm{S}$ (light blue) and $60^{\circ} \mathrm{S}-90^{\circ} \mathrm{S}$ (violet) in September relative to the 1970-1979 average for the MPA scenario.

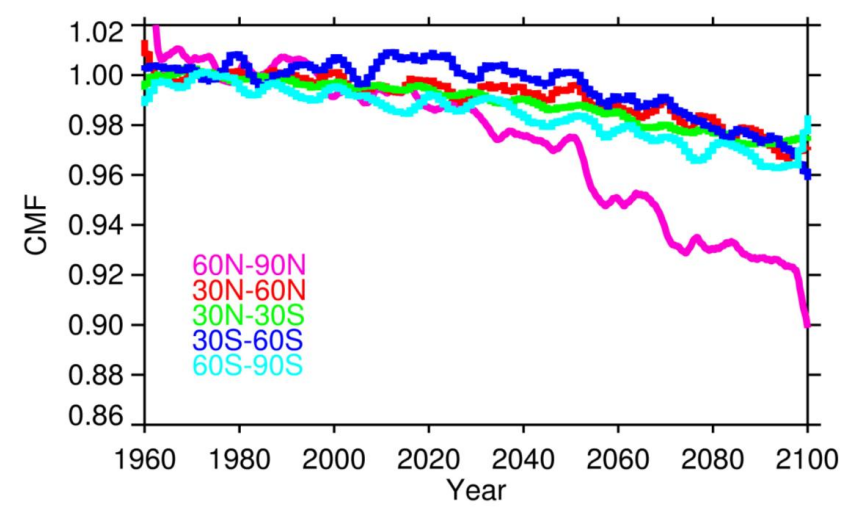

Fig. 14. Cloud modification factor (CMF) changes relative to the 1970-1979 average. A decrease in CMF corresponds to a decreased cloud transmission, i.e., a decrease in transmitted solar radiation to the surface.

values than found in the pre-ozone-hole period, but only by $5 \%$ to $10 \%$. Larger decreases are observed at higher latitudes: in the Northern Hemisphere, UV radiation decreases by more than $20 \%$, while in the Southern Hemisphere, UV radiation decreases by nearly $50 \%$ due to the disappearance of the ozone hole over the Antarctic. While ozone changes have a well documented influence on the future evolution of the UV radiation, cloud changes need to be taken into account in this scenario as well so that the parameters affecting future UV changes can be quantified.

As shown by Bais et al. (2011), cloud effects in CCMs are responsible for $2-3 \%$ of the reduction in surface erythemal solar irradiance at high latitudes and up to $1 \%$ at mid-latitudes. In CCM SOCOL, cloud transmission changes show an overall decreasing trend, as evidenced in Fig. 14 for the five latitudinal bands. The largest changes are seen in the high northern latitudes with a relative decrease in cloud modification factor of $10 \%$, while at lower latitudes and in the Southern Hemisphere CMFs remain more or less constant with changes of less than $4 \%$ between the 1960s and 2100. Thus, CCM SOCOL predicts an overall slight increase in cloud cover or cloud thickness, which is in opposition to currently observed cloud trends (Gröbner and Wacker, 2011; Maugeri et al., 2001; Trenberth et al., 2007; Smedley et al., 2012). Seeing that the future UV trends will significantly depend on the changes in cloud cover, increased efforts to model cloud changes in CCM models will be required to better predict future UV levels.

Since future aerosol scenarios were not taken into account in this model-run, modelled changes in UV radiation are, therefore, dominated by changes in the total column ozone and cloud cover.

\section{Conclusions}

In this article, we evaluate the usefulness of international agreements such as the Montreal Protocol on the basis of numerical experiments carried out with the modern chemistryclimate model SOCOL in the framework of the CCMVal campaign. Analysis of the simulated data allows the following conclusions. In the absence of the MPA by 2100 , the mesosphere and stratosphere cool down by $40 \mathrm{~K}$ and $20 \mathrm{~K}$, respectively, as a consequence of dramatic ozone depletion, which by the end of the 21 st century could exceed $80 \%$. For the total ozone the simulated benefits of the MPA reaches $50 \%$ in the tropical latitudes and $70-80 \%$ in high latitudes of both hemispheres. For the global annual ozone benefits of the MPA reach $50 \%$ by the 2050 and $80 \%$ by the 2100 . The tropospheric ozone depletion by additional halogens and less ozone influx from the stratosphere reaches $60-80 \%$. The comparison with the results of Newman et al. (2009) demonstrates that the absence of tropospheric chemistry would lead to substantial underestimation of this effect, while a good agreement with the results of Morgenstern et al. (2008) allows to conclude that the additional ozone production due to increased UV does not play substantial role. Pronounced ozone depletion leads to substantial alteration of the strength by up to $40 \mathrm{~m} \mathrm{~s}^{-1}$ and latitudinal location by up to $20^{\circ}$ of the polar vortices, increase of the BDC intensity by up to $100 \%$ and shift of the NAM to negative phase. In the absence of the MPA, we model substantial changes in surface temperature over Europe and Russian Federation, and Poles as well as some changes in precipitation. The obtained changes of the circulation and climate should be taken with caution because the absence of an interactive ocean in our model and these issues require further investigations with more sophisticated models. When the Montreal Protocol limitations are not implemented, UV radiation undergoes a dramatic increase in the 21 st century, with 5-fold increases in populated areas, corresponding to UV Index values in excess of 50 in the summer months. In contrast, UV levels tend to decrease in the 21 st century under the Montreal Protocol scenario, by $5 \%$ 
to $10 \%$ at middle latitudes with respect to the "pre-ozone hole" period. This decrease is partly due to an increase in total column ozone in excess of the ozone levels found in the 1960s, but also due to an increase in overall cloud cover, as estimated by CCM SOCOL. We find that expected ozone increases and changes in clouds have quantitatively similar influences on future surface UV radiation levels. Therefore, cloud processes and their radiative impacts need to be further studied in CCM model validation studies to better constrain this important parameter. All our results confirm the important role of the Montreal Protocol in protecting the ozone layer and the Earth climate. The estimation of the MPA benefits for the future climate changes can not be fully addressed in this paper and requires new experiments using Earth System models.

Acknowledgements. This work was supported by the European Community's Seventh Framework Programme (FP7/20072013) under grant agreement No. 218816 (SOTERIA project, http://www.soteria-space.eu. We thank two anonymous referees for their helpful comments.

Edited by: R. Müller

\section{References}

Bais, A. F., Tourpali, K., Kazantzidis, A., Akiyoshi, H., Bekki, S., Braesicke, P., Chipperfield, M. P., Dameris, M., Eyring, V., Garny, H., Iachetti, D., Jockel, P., Kubin, A., Langematz, U., Mancini, E., Michou, M., Morgenstern, O., Nakamura, T., Newman, P. A., Pitari, G., Plummer, D. A., Rozanov, E., Shepherd, T. G., Shibata, K., Tian, W., and Yamashita, Y.: Projections of UV radiation changes in the 21 st century: impact of ozone recovery and cloud effects, Atmos. Chem. Phys., 11, 7533-7545, doi:10.5194/acp-11-7533-2011, 2011.

Butchart, N., Charlton-Perez, A., Cionni, I., Hardiman, S., Haynes, P., Krüger, K., Kushner, P., Newman, P., Osprey, S., Perlwitz, J., Sigmond, M., Wang, L., Akiyoshi, H., Austin, J., Bekki, S., Baumgaertner, A., Braesicke, P., Brühl, C., Chipperfield, M., Dameris, M., Dhomse, S., Eyring, V., Garcia, R., Garny, H., Jöckel, P., Lamarque, J.-F., Marchand, M., Michou, M., Morgenstern, O., Nakamura, T., Pawson, S., Plummer, D., Pyle, J., Rozanov, E., Scinocca, J., Shepherd, T., Shibata, Smale, D., Teyssèdre, H., Tian, W., Waugh, D., and Yamashita, Y.: Multimodel climate and variability of the stratosphere, J. Geophys. Res., 116, D05102, doi:10.1029/2010JD014995, 2011.

Den Outer, P. N., Slaper, H., and Tax, R. B.: UV radiation in the Netherlands: Assessing long-term variability and trends in relation to ozone and clouds, J. Geophys. Res.-Atmos., 110, D02203, doi:10.1029/2004JD004824, 2005.

Egorova, T., Rozanov, E., Zubov, V., and Karol, I.: Model for investigating ozone trends (MEZON), Izvestiya, Atmos. Ocean. Phys., 39, 277-292, 2003.

Egorova, T., Rozanov, E., Zubov, V., Manzini, E., Schmutz, W., and Peter, T.: Chemistry-climate model SOCOL: a validation of the present-day climatology, Atmos. Chem. Phys., 5, 1557-1576, doi:10.5194/acp-5-1557-2005, 2005.
Egorova, T., Rozanov, E., Gröbner, J., Hauser, M., and Schmutz, W.: Montreal Protocol benefits simulated with CCM SOCOL, Atmos. Chem. Phys. Discuss., 12, 17001-17030, doi:10.5194/acpd-12-17001-2012, 2012.

Egorova, T. A., Rozanov, E. V., Schlesinger, M. E., Andronova, N. G., Malyshev, S. L., Karol, I. L., and Zubov, V. A.: Assessment of the effect of the Montreal Protocol on atmospheric ozone, Geophys. Res. Lett., 28, 2389-2392, 2001.

Eyring, V., Butchart, N., Waugh, D. W., Akiyoshi, H., Austin, J., Bekki, S., Bodeker, G. E., Boville, B. A., Chipperfield, M. P., Cordero, E., Dameris, M., Deushi, M., Fioletov, V. E., Frith, S. M., Garcia, R. R., Gettelman, A., Giorgetta, M. A., Greve, V., Jourdain, L., Kinnison, D. E., Mancini, E., Manzini, E., Marchand, M., Marsh, D. R., Nagashima, T., Newman, P. A., Nielsen, J. E., Pawson, S., Pitari, G., Plummer, D. A., Rozanov, E., Schraner, M., Shepherd, T. G., Schibata, K., Stolarski, R. S., Struthers, H., Tian, W., and Yoshiki, M.: Assessment of Temperature, Trace Species, and Ozone in Chemistry-Climate Model Simulation of the Recent Past, J. Geophys. Res., 111, D22308, doi:10.1029/2006JD007327, 2006.

Eyring, V., Waugh, D. W., Bodeker, G. E., Cordero, E., Akiyoshi, H., Austin, J., Beagley, S. R., Boville, B., Braesicke, P., Brühl, C., Butchart, N., Chipperfield, M. P., Dameris, M., Deckert, R., Deushi, M., Frith, S. M., Garcia, R. R., Gettelman, A., Giorgetta, M., Kinnison, D. E., Mancini, E., Manzini, E., Marsh, D. R., Matthes, S., Nagashima, T., Newman, P. A., Nielsen, J. E., Pawson, S., Pitari, G., Plummer, D. A., Rozanov, E., Schraner, M., Scinocca, J. F., Semeniuk, K., Shepherd, T. G., Shibata, K., Steil, B., Stolarski, R., Tian, W., and Yoshiki, M.: Multi-model Projections of Stratospheric Ozone in the 21st Century, J. Geophys. Res., 112, D16303, doi:10.1029/2006JD008332, 2007.

Eyring, V., Cionni, I., Bodeker, G. E., Charlton-Perez, A. J., Kinnison, D. E., Scinocca, J. F., Waugh, D. W., Akiyoshi, H., Bekki, S., Chipperfield, M. P., Dameris, M., Dhomse, S., Frith, S. M., Garny, H., Gettelman, A., Kubin, A., Langematz, U., Mancini, E., Marchand, M., Nakamura, T., Oman, L. D., Pawson, S., Pitari, G., Plummer, D. A., Rozanov, E., Shepherd, T. G., Shibata, K., Tian, W., Braesicke, P., Hardiman, S. C., Lamarque, J. F., Morgenstern, O., Pyle, J. A., Smale, D., and Yamashita, Y.: Multimodel assessment of stratospheric ozone return dates and ozone recovery in CCMVal-2 models, Atmos. Chem. Phys., 10, 94519472, doi:10.5194/acp-10-9451-2010, 2010.

Farman, J. C., Gardiner, B. G., and Schaklin, J. D.: Large losses of the total ozone in Antarctica reveal seasonal $\mathrm{ClO}_{\mathrm{x}} / \mathrm{NO}_{\mathrm{x}}$ interaction, Nature, 315, 207-210, 1985.

Forster, P., Fomichev, V., Rozanov, E. , Cagnazzo, C., Jonsson, A. I., Langematz, U., Fomin, B., Iacono, M. J., Mayer, B., Mlawer, E., Myhre, G. , Portmann, R. W., Akiyoshi, H., Falaleeva, V., Gillett, N., Karpechko, A., Li, J., Lemennais, P., Morgenstern, O., Oberländer, S., Sigmond, M., and Shibata, K.: Evaluation of radiation scheme performance within chemistry climate models, J. Geophys. Res., 116, D10302, doi:10.1029/2010JD015361, 2011.

Garcia, R. R., Kinnison, D. E., and Marsh, D. R.: "World avoided" simulations with the Whole Atmosphere Community Climate Model, J. Geophys. Res., 117, D23303, doi:10.1029/2012JD018430, 2012.

Gröbner, J. and Wacker, S.: Lonwave Radiation at Davos and implications for cloud changes, GAW-CH Conference 18-19 January 
2011, Zurich, Switzerland, www.meteoschweiz.admin.ch/web/ de/klima/klima_international/gaw-ch/gaw_ch_conference.html, 2011.

Hegglin, M. I. and Shepherd, T. G.: Large climate-induced changes in ultraviolet index and stratosphere-to-troposphere ozone flux, Nat. Geosci., 2, 687-691, doi:10.1038/Ngeo604, 2009.

Intergovernmental Panel on Climate Change (IPCC): Climate change 2001: The Scientific Basis. Contribution of Working Group I to the Third Assessment Report of the Intergovernmental Panel on Climate Change, edited by: Houghton, J. T., Ding, Y., Griggs, D. J., Noguer, M., van der Linden, P. J., Dai, X., Maskell, K., and Johnson, C. A., 881 pp., 4/3/02, Cambridge Univ. Press, Cambridge, UK, 2001.

Intergovernmental Panel on Climate Change (IPCC), Climate change 2007: The Physical Scienc Basis. Contribution of Working Group I to the Fourth Assessment Report of the Intergovernmental Panel on Climate Change, edited by: Solomon, S., Qin, D., Manning, M., Chen, Z., Marquis, M., Averyt, K. B., Tignor, M., and Miller, H. L., 996 pp., Cambridge Univ. Press, Cambridge, UK, 2007.

Karpechko, A. Yu., Gillett, N. P., Hassler, B., Rosenlof, K. H., and Rozanov, E.: Quantitative assessment of Southern Hemisphere ozone in chemistry-climate model simulations, Atmos. Chem. Phys., 10, 1385-1400, doi:10.5194/acp-10-1385-2010, 2010.

Manzini, E., McFarlane, N., and McLandress, C.: Impact of the Doppler spread parameterization on the simulation of the middle atmosphere circulation using the MA/ECHAM4 general circulation model, J. Geophys. Res., 102, 25751-25762, doi:10.1029/97JD01096, 1997.

Maugeri, M., Bagnati, Z., and Brunetti, M.: Trends in Italian total cloud amount, 1951-1996, Geophys. Res. Lett., 28, 4551-4554, 2001.

Mayer, B. and Kylling, A.: Technical note: The libradtran software package for radiative transfer calculations - description and examples of use, Atmos. Chem. Phys., 5, 1855-1877, doi:10.5194/acp-5-1855-2005, 2005.

McKenzie, R., Smale, D., Bodeker, G., and Claude, H.: Ozone pro?le differences between Europe and New Zealand: Effects on surface UV irradiance and its estimation from satellite sensors, J. Geophys. Res., 108, 4179, doi:10.1029/2002JD002770, 2003.

Meehl, G. A., Stocker, T. F., Collins, W. D., Friedlingstein, P., Gaye, A. T., Gregory, J. M., Kitoh, A., Knutti, R., Murphy, J. M., Noda, A., Raper, S. C. B., Watterson, I. G., Weaver, A. J., and Zhao, Z.-C.: Global Climate Projections, in: Climate Change 2007: The Physical Science Basis, Contribution of Working Group I to the Fourth Assessment Report of the Intergovernmental Panel on Climate Change, edited by: Solomon, S., Qin, D., Manning, M., Chen, Z., Marquis, M., Averyt, K. B., Tignor, M., and Miller, H. L., Cambridge University Press, Cambridge, United Kingdom and New York, NY, USA, 2007.

Morgenstern, O., Braesicke, P., Hurwitz, M. M., O’Connor, F. M., Bushell, A. C., Johnson, C. E., and Pyle, J. A.: The world avoided by the Montreal Protocol, Geophys. Res. Lett., 35, L16811, doi:10.1029/2008GL034590, 2008.

Morgenstern, O., Giorgetta, M. A, Shibata, K., Eyring, V., Waugh,D. W., Shepherd, T. G., Akiyoshi, H., Austin, J., Baumgaertner, A. J. G., Bekki, S., Braesicke, P., Brühl, C., Chipperfield, M. P., Cugnet, D., Dameris, M., Dhomse, S., Frith, S. M., Garny, H., Gettelman, A., Hardiman, S. C., Hegglin, M. I., Kin- nison, D. E., Lamarque, J.-F., Mancini, E., Manzini, E., Marchand, M., Michou, M., Nakamura, T., Nielsen, J. E., Pitari, G., Plummer, D. A., Rozanov, E., Scinocca, J. F., Smale, D., Teyssedre, H., Toohey, M., Tian, W., and Yamashita, Y.: Review of the formulation of present-generation stratospheric chemistryclimate models and associated external forcings, J. Geophys. Res.-Atmos., 115, D00M02, doi:10.1029/2009jd013728, $2010 \mathrm{a}$. Morgenstern, O., Akiyoshi, H., Bekki, S., Braesicke, P., Butchart, N., Chipperfield, M., Cugnet, D., Deushi, M., Dhomse, S., Garcia, R., Gettelman, A, Gillett, N., Hardiman, S., Jumelet, J, Kinnison, D., Lamarque, J.-F., Lott, F., Marchand, M., Michou, M., Nakamura, T., Olivie, D., Peter, T., Plummer, D., Pyle, J., Rozanov, E., Saint-Martin, D., Scinocca, J., Shibata, K., Sigmond, M., Smale, D., Teyssedre, H., Tian, W., Voldoire, A., and Yamashita, Y.: Anthropogenic forcing of the Northern Annular Mode in CCMVal-2 models, J. Geophys. Res., 115, D00M03, doi:10.1029/2009JD013347, 2010b.

Newman, P. A., Oman, L. D., Douglass, A. R., Fleming, E. L., Frith, S. M., Hurwitz, M. M., Kawa, S. R., Jackman, C. H., Krotkov, N. A., Nash, E. R., Nielsen, J. E., Pawson, S., Stolarski, R. S., and Velders, G. J. M.: What would have happened to the ozone layer if chlorofluorocarbons (CFCs) had not been regulated?, Atmos. Chem. Phys., 9, 2113-2128, doi:10.5194/acp-9-2113-2009, 2009.

Newmann, P. A. and McKenzie, R.: UV impacts avoided by the Montreal Protocol, Photochem. Photobiol. Sci., 10, 1152-1160, 2011.

Prather, M., Midgley, P., Sherwood Rowland, F., and Stolarski, R.: The ozone layer: The road not taken, Nature, 381, 551-554, doi:10.1038/381551a0, 1996.

Roeckner, E., Bäuml, G., Bonaventura, L., Brokopf, R., Esch, M., Giorgetta, M., Hagemann, S., Kirchner, I., Kornblueh, L., Manzini, E., Rhodin, A., Schlese, U., Schulzweida, U., and Tompkins, A.: The atmospheric general circulation model EHAM5. Part I: Model description, Rep. 218, 90 pp., MaxPlanck-Ins. Für Meteorol., Hamberg, Germany, 2003.

Roeckner, E., Brokopf, R., Esch, M, Giorgetta, M., Hagemann, S., Kornblueh, L., Manzini, E., Schlese, U., and Schulzweida, U.: The atmospheric general circulation model EHAM5. Part II: Sencetivity of simulated climate to horizontal and vertical resolution, Rep. 354, Max-Planck-Ins. Für Meteorol., Hamburg, Germany, 2004.

Rozanov, E., Schlesinger, M., Zubov, V., Yang, F., and Andronova, N.: TheUIUC three-dimensional stratospheric chemical transport model: description and evaluation of the simulated source gases and ozone, J. Geophys. Res., 104, 11755-11781, 1999.

Schraner, M., Rozanov, E., Schnadt Poberaj, C., Kenzelmann, P., Fischer, A. M., Zubov, V., Luo, B. P., Hoyle, C. R., Egorova, T., Fueglistaler, S., Brönnimann, S., Schmutz, W., and Peter, T. Chemistry-climate model SOCOL: version 2.0 with improved transport and chemistry/microphysics schemes, Atmos. Chem. Phys. 8, 5957-5974, doi:10.5194/acp-8-5957-2008, 2008.

Shepherd, T. and McLandress, C.: A robust mechanism for strengthening of the Brewer-Dobson circulation under climate change: Critical-layer control of subtropical wave breaking, J. Atmos. Sci., 68, 784-797, 2011.

Shettle, E. P.: Models of aerosols, clouds and precipitation for atmospheric propagation studies, AGARD Conference Proceedings: Atmospheric Propagation in the UV, Visible, IR and MM-Wave 
Region and Related Systems Aspects (ASA221594), No. 454, 1990.

Smedley, A. R., Rimmer, J. S., More, D., Toumi, R., and Webb, A. R.: Total ozone and surface trends in the United Kingdom: 19792008, Int. J. Climatol., 32, 338-346, doi:10.1002/joc.2275, 2012.

SPARC CCMVal: SPARC Report on the Evaluation of ChemistryClimate Models, edited by: Eyring, V., Shepherd, T. G., and Waugh, D. W., SPARC Rep. 5, WCRP-132, WMO/TD 1526, World Clim. Res. Program, Toronto, Ont., Canada, 2010.

Stamnes, K., Tsay, S. C., Wiscombe, W., and Jayaweera, K.: Numerically stable algorithm for discrete-ordinate-method radiative-transfer in multiple-scattering and emitting layered media, App. Opt., 27, 2502-2509, 1988.

Trenberth, K. E., Jones, P. D., Ambenje, P., Bojariu, R., Easterling, D., Klein Tank, A., Parker, D., Rahimzadeh, F., Renwick, J. A., Rusticucci, M., Soden, B., and Zhai, P.: Observations: Surface and Atmospheric Climate Change. In: Climate Change 2007: The Physical Science Basis, Contribution of Working Group I to the Fourth Assessment Report of the Intergovernmental Panel on Climate Change, edited by: Solomon, S., Qin, D., Manning, M., Chen, Z., Marquis, M., Averyt, K. B., Tignor, M., and Miller, H. L., Cambridge University Press, Cambridge, UK and New York, NY, USA, 2007.

Tourpali, K., Bais, A. F., Kazantzidis, A., Zerefos, C. S., Akiyoshi, H., Austin, J., Brühl, C., Butchart, N., Chipperfield, M. P., Dameris, M., Deushi, M., Eyring, V., Giorgetta, M. A., Kinnison, D. E., Mancini, E., Marsh, D. R., Nagashima, T., Pitari, G., Plummer, D. A., Rozanov, E., Shibata, K., and Tian, W.: Clear sky uv simulations for the 21 st century based on ozone and temperature projections from chemistry-climate models, Atmos. Chem. Phys., 9, 1165-1172, doi:10.5194/acp-9-1165-2009, 2009.
Velders, G. J. M., Andersen, S. O., Daniel, J. S., Fahey, D. W., and McFarland, M.: The importance of the Montreal Protocol in protecting climate, Proc. Natl. Acad. Sci. USA, 104, 4814-4819, doi:10.1073/pnas.0610328104, 2007.

World Meteorological Organization (WMO): Scientific assessment of ozone depletion: 1998, Global Ozone Res. Monit. Proj. Rep. 44, Geneva, Switzerland, 1999.

World Meteorological Organization (WMO): Scientific assessment of ozone depletion: 2006, Global Ozone Res. Monit. Proj. Rep. 50, Geneva, Switzerland, 2007.

World Meteorological Organization (WMO): Scientific assessment of ozone depletion: 2010, Global Ozone Research and Monitoring Project, Report No. 52, Geneva, Switzerland, 2011.

Wu, Y., Polvani, L. M., and Seager, R.: The Importance of the Montreal Protocol in Protecting the Earth's Hydroclimate, J. Clim., doi:10.1175/JCLI-D-12-00675.1, 2012.

Zubov, V. A., Rozanov, E. V., and Schlesinger, M. E.: Hybrid Scheme for 3-Dimensional Advective Transport, Mon. Weather Rev. 27, 1335-1346, 1999. 